\title{
O SUB-CAMPO DO FUTEBOL: PRESIDENTES DE CLUBES EM FOCO
}

\author{
Renato Francisco Rodrigues Marques, Universidade de São Paulo - USP, São Paulo - \\ Brasil \\ Diego Monteiro Gutierrez, Universidade de São Paulo - USP, São Paulo - Brasil \\ Marco Antônio Bettine de Almeida, Universidade de São Paulo - USP, São Paulo - Brasil
}

\section{RESUMO}

As relações sociais no futebol brasileiro expressam legitimação política e social que respeitam critérios próprios e em parte divergem da moralidade da sociedade contemporânea. O objetivo deste estudo foi investigar o espaço da administração e relações de poder referentes aos presidentes de clubes atuantes no futebol profissional no país. Buscou-se caracterizar esse agente e identificar seu habitus pela observação de trajetórias pessoais e características simbólicas do ambiente organizacional em que atuam. Os dados foram coletados com pesquisa em home pages de clubes de futebol, sites especializados e jornais esportivos digitais. Os resultados, com discussão baseada na obra de Pierre Bourdieu, demonstram que os presidentes fazem parte de uma elite profissional e que possuem como capital simbólico a capacidade gestora e de geração de lucros em clubesempresa; a lealdade e vínculo duradouro com o clube sócio-esportivo em grandes centros; e forte relação política com o município-sede da entidade em pequenas cidades.

Palavras-Chave: Futebol; Sociologia; Política.

\section{SOCCER SUB-SPACE: CLUBS PRESIDENTS IN FOCUS}

\begin{abstract}
Social relations in Brazilian football express political and social legitimacy that respect their own criteria, which differ in part of the morality of contemporary society. The objective of this study was to investigate the area of administration and power relations related to the presidents of professional football clubs operating in the country. We sought to characterize the agent and identifying their habitus, by observing personal trajectories and symbolic characteristics of the organizational environment in which they operate. Data were collected with research on home pages of football clubs, websites and digital sports newspaper. The results, with discussion based on the theory of Pierre Bourdieu, demonstrate that presidents are part of professional elite and have as symbolic capital management and the ability to generate profits, in business clubs; loyalty and lasting bond with the club membership in big cities; and strong political relationship with the countyseat of the club in small towns.
\end{abstract}

Key-Words: Soccer; Sociology; Politics.

Conexões: revista da Faculdade de Educação Física da UNICAMP, Campinas, v. 11, n. 1, p.188-203, jan../mar. 2013. 188 ISSN: 1983-9030 


\section{INTRODUÇÃO}

Uma das principais formas de manifestação do esporte contemporâneo é o futebol. Assim como outros fenômenos socioculturais, sofre e exerce diferentes modos de influência em relação ao espaço social, com inserções políticas, morais e econômicas. O estudo sobre meios de socialização presentes neste ambiente se coloca como forma de melhor entender o próprio esporte e a sociedade, possibilitando uma melhor gestão e interação com esta importante modalidade esportiva.

Como meio de análise sociocultural a respeito do futebol no Brasil, este trabalho foca sua atenção sobre os presidentes de clubes profissionais masculinos desta modalidade no país e sua atuação social no sub-campo futebolístico. A sociologia do esporte se apresenta como alternativa e meio de abordagem científica. Nesse processo de pesquisa social insere-se a necessidade de adoção de referenciais teóricos ligados a essa forma de conhecimento, delimitando diretrizes de trabalho e critérios de análise.

\section{O Clube de Futebol como Espaço de Convívio e Organização Esportiva}

O futebol no Brasil desenvolve-se essencialmente a partir da formação e atuação dos atletas nos clubes. Esta realidade, contudo, é menos homogênea do que parece, em função de diferentes fatores como:
a. tradição e história;
b. número de associados;
c. objetivos;
d. base geográfica, entre outros.

Galatti, ${ }^{1}$ com base em Puig et al. ${ }^{2}$ e Heinemann, ${ }^{3}$ apresenta uma tipologia própria sobre diferentes estruturas que clubes envolvidos com o esporte podem adotar:

1. Clube distintivo: considerados elitistas, reúnem associados das classes média e alta que praticam esportes clássicos (como tênis, golfe ou hipismo) organizando competições internas ou competindo com outros clubes, sem aspirações ao profissionalismo. Reúne grande número de associados (normalmente mais de 500) para suprir os gastos elevados, dos quais muitos são inativos, mas mantém 
o associacionismo por status e prestígio. Está relacionado ao lazer e alavanca grande rede de contatos sociais com organização de festas e outros eventos.

2. Clubes integrados: são constituídos por grupos específicos que desejam manter aspectos de uma determinada identidade de grupo, como imigrantes que preservam nos clubes as tradições de seu país ou trabalhadores de setores específicos. Nem sempre apresentam sede, reunindo-se para a prática esportiva em espaços públicos.

3. Clube esportivo: Em geral, são clubes de porte pequeno (cerca de 300 associados) especializados em uma modalidade esportiva específica. Participam de competições e estão vinculados a uma federação que as organizam, determinando e interpretando regras, organizando ligas, associando-se a federações etc. Assim, a vida do clube se centra na formação de atletas e organização de campeonatos. Isso demanda gastos com taxas e logística de competição, treinadores fixos e, por vezes, atletas remunerados, sendo os pagamentos efetuados pelos associados insuficientes para manter o clube, que dependem de outras fontes, como patrocínios, mecenas, vendas de ingressos para partidas, entre outros. Essa dependência de fontes secundárias de renda se apresenta como um risco para o desenvolvimento do clube no caso de uma interrupção nos rendimentos provenientes dessas fontes.

4. Uniões: estão ligados a uma causa além da oferta e prática esportiva, como a preservação da natureza ou a predileção por um tipo de automóvel, entre outros. Atraem grande número de associados (por vezes mais de 5000), muitos não pela prática do esporte, mas pela causa que se defende por meio do fenômeno esportivo.

5. Associações de esporte tradicional: visa à manutenção de modalidades tradicionais de regiões determinadas.

6. Associações de esporte para todos: busca atender a objetivos opostos ao esporte

Conexões: revista da Faculdade de Educação Física da UNICAMP, Campinas, v. 11, n. 1, p.188-203, jan../mar. 2013.190 ISSN: 1983-9030 
profissional e representativo, e aos princípios que caracterizaram o esporte moderno, buscando integrar diferentes grupos na e pela prática esportiva, como idosos, pessoas com deficiência ou grupos marginalizados. Oferecem ampla variedade de modalidades esportivas e outras atividades físicas com objetivo de melhora da saúde e da condição física, assim como aspectos socioculturais.

7. Clubes profissionais: tem o foco na oferta do esporte com fins de espetáculo, sendo parte da indústria esportiva, empregando atletas profissionais a partir da arrecadação de fundos através de patrocínios e espectadores. Está relacionado com a manutenção da identidade local.

Nota-se que no Brasil, o futebol estrutura-se principalmente sobre os clubes sócioesportivos (nomenclatura adotada para sintetizar uma realidade no país, a qual envolve as definições de clube esportivo e associações de esporte para todos, por estarem relacionados à atenção ao lazer dos sócios e às atividades esportivas profissionais) e clubes-empresa (similares aos clubes profissionais, subordinados às mesmas legislações de empresas particulares).

Ao observar a realidade dos clubes de futebol no Brasil percebe-se certa pluralidade, tanto pela presença dos clubes-empresa, como também pelas diferenças de tamanho e tradição. De uma forma geral, os clubes mais antigos mantêm o formato sócio-esportivo, enquanto os menores e mais novos apresentam maior diversidade. Todos os clubes possuem a figura do presidente. No caso do sócio-esportivo, eleito a partir de consulta entre os membros. No caso dos clubes-empresa, por indicação dos proprietários.

\section{OBJETIVOS DO ESTUDO}

O objetivo geral deste trabalho foi investigar e delimitar uma esfera específica do subcampo esportivo do futebol, o nicho da administração e relações de poder referentes aos presidentes das entidades envolvidas neste espaço social.

O objetivo específico deste trabalho foi conhecer a figura e identificar o habitus do grupo social dos presidentes de clube de futebol a partir da observação de suas trajetórias 
pessoais, das características materiais e simbólicas do ambiente organizacional em que atuam e do sub-campo do futebol.

\section{MATERIAIS E MÉTODOS}

Este estudo adota, como referencial metodológico, contribuições da sociologia de Pierre Bourdieu, procurando perceber o presidente do clube de futebol profissional enquanto agente social, que age de acordo com seu habitus no sub-campo do futebol, no contexto de uma cultura específica e determinada.

A pesquisa realizada caracteriza-se como exploratório-descritiva, com o objetivo de descrever um espaço social específico, dedicando especial ênfase a um grupo determinado de agentes atuantes, os presidentes de clubes.

O primeiro passo da pesquisa foi listar alguns dos clubes que participam das principais competições nacionais masculinas e profissionais (séries A e B do Campeonato Brasileiro e dos principais campeonatos estaduais) e também os campeões brasileiros nos últimos vinte anos. A partir desta informação, foi traçada a história e perfil pessoal dos presidentes das agremiações, a partir de home pages oficiais das equipes envolvidas, em sites especializados em futebol e em jornais esportivos em versão digital. Na posse destes dados foi construída uma tipologia de análise, agregando as principais características em conjuntos relativamente homogêneos, para construir grupos sociais que permitam uma reflexão sistematizada sobre o objeto de estudo, relacionando-o com as categorias propostas por Pierre Bourdieu.

O resultado final é a apresentação de um quadro amplo e complexo do cenário dos clubes brasileiros de futebol masculino profissional, tendo como recorte principal a figura dos presidentes, numa perspectiva de análise original com relação às pesquisas realizadas tanto no Brasil como no exterior.

\section{RESULTADOS E DISCUSSÃO}

\section{O Clube de Futebol Pprofissional no Brasil}

Conexões: revista da Faculdade de Educação Física da UNICAMP, Campinas, v. 11, n. 1, p.188-203, jan../mar. 2013. 192 ISSN: 1983-9030 
As mais de 400 equipes profissionais listadas no ranking da Confederação Brasileira de Futebol têm seus campeonatos e disputas extra-campo organizados por instituições em níveis diferenciados (mundial, continental, nacional e regional). $\mathrm{O}$ formato dos campeonatos está a cargo das entidades reguladoras (confederações, federações, associações, ligas) e varia de acordo com a preferência e o número de equipes. Por exemplo, o Campeonato Paulista possui mais de 100 equipes divididas em quatro divisões, as três primeiras com 20 times e a última com 40 .

Os torneios nacionais são a Copa do Brasil e o Campeonato Brasileiro. O primeiro é organizado de modo a abarcar equipes maiores e indicações das federações. O segundo é dividido em quatro divisões (Séries A, B, C e D), nas quais as equipes permanecem, ascendem ou descendem, de acordo com um processo meritocrático de resultados. Cada entidade (federação) regional organiza seu campeonato estadual (também formado por divisões ou séries).

Os clubes de futebol no Brasil são administrados de diversas formas, mas podem ser divididos em dois grupos principais, os clubes sócio-esportivos, maioria e mais tradicionais, e os clubes-empresa, normalmente mais recentes. Dentro desses grupos existem variações e algumas formas alternativas que são fruto da situação específica de cada agremiação.

Conexões: revista da Faculdade de Educação Física da UNICAMP, Campinas, v. 11, n. 1, p.188-203, jan../mar. 2013.193 ISSN: 1983-9030 
Quadro 1 - Exemplos de alguns clubes sócio-esportivos

\begin{tabular}{|c|c|c|}
\hline $\begin{array}{c}\text { Clube/ } \\
\text { Fundação original/ Ano de } \\
\text { introdução do futebol }\end{array}$ & $\begin{array}{l}\text { Poliesportivo / } \\
\text { Recreacional / Outra } \\
\text { modalidade/ } \\
\text { profissional }\end{array}$ & Especificidade \\
\hline $\begin{array}{l}\text { Flamengo-RJ/ Regatas } \\
1898 / 1912\end{array}$ & $\mathrm{Sim} / \mathrm{Sim} / \mathrm{Sim}$ & $\begin{array}{l}\text { Alem de títulos em várias modalidades } \\
\text { presidido por uma ex-nadadora do clube }\end{array}$ \\
\hline $\begin{array}{l}\text { Vasco da Gama-RJ/ } \\
\text { Regatas } 1898 / 1915\end{array}$ & Sim / Sim/ Sim & \\
\hline $\begin{array}{l}\text { Fluminense-RJ/ Futebol } \\
1902\end{array}$ & $\mathrm{Sim} / \mathrm{Sim} / \mathrm{Sim}$ & $\begin{array}{l}\text { Foi o primeiro clube carioca voltado } \\
\text { exclusivamente para o futebol e que construiu } \\
\text { uma arena poliesportiva }\end{array}$ \\
\hline $\begin{array}{l}\text { Botafogo-RJ/ Regatas } \\
1894 / 1904\end{array}$ & $\mathrm{Sim} / \mathrm{Sim} / \mathrm{Sim}$ & \\
\hline $\begin{array}{l}\text { São Paulo-SP/ Futebol } \\
1935\end{array}$ & Sim / Sim / Não & \\
\hline $\begin{array}{l}\text { Corinthians-SP/ Futebol } \\
1910\end{array}$ & $\mathrm{Sim} / \mathrm{Sim} / \mathrm{Sim}$ & $\begin{array}{l}\text { A introdução de outros esportes foi posterior. } \\
\text { remo, fundado em 1930, está representado no } \\
\text { escudo do clube }\end{array}$ \\
\hline $\begin{array}{l}\text { Palmeiras-SP/ Futebol } \\
1914\end{array}$ & $\mathrm{Sim} / \mathrm{Sim} / \mathrm{Sim}$ & \\
\hline Santos-SP/Futebol 1912 & Sim / Não/ Sim & $\begin{array}{l}\text { A introdução de outras modalidades no clube } \\
\text { recente }\end{array}$ \\
\hline $\begin{array}{l}\text { Cruzeiro-MG/ Futebol } \\
1921\end{array}$ & $\mathrm{Sim} / \mathrm{Sim} / \mathrm{Sim}$ & $\begin{array}{l}\text { A sede poliesportiva está mais voltada para a } \\
\text { recreação do sócio do que a prática de esportes } \\
\text { competitivos, com destaque também para } \\
\text { atletismo }\end{array}$ \\
\hline $\begin{array}{l}\text { Atlético-MG/ Futebol } \\
1908\end{array}$ & $\mathrm{Sim} / \mathrm{Sim} / \mathrm{Sim}$ & $\underline{-}$ \\
\hline $\begin{array}{l}\text { Internacional-RS/ Futebol } \\
1909\end{array}$ & Não / Não/ Sim & $\begin{array}{l}\text { O clube competiu de forma esporádica em outras } \\
\text { modalidades que acabaram desativadas, mas em } \\
2009 \text { retomou a prática, objetivando formar } \\
\text { atletas para os Jogos Olímpicos de } 2016 \text {. Não } \\
\text { tem uma estrutura poliesportiva voltada para o } \\
\text { sócio, o que não impede de ser o clube com o } \\
\text { maior número de associados no Brasil }\end{array}$ \\
\hline Gremio-RS/ Futebol 1903 & Não / Não / Não & $\begin{array}{l}\text { O clube não tem envolvimento em outras } \\
\text { modalidades e nem sede social, mas possui um } \\
\text { grande número de sócios }\end{array}$ \\
\hline $\begin{array}{l}\text { Coritiba-PR/ Futebol } \\
1909\end{array}$ & Não / Não / Não & ב_ \\
\hline $\begin{array}{l}\text { Vitoria-BA/Cricket } 1899 \\
\text { / } 1899\end{array}$ & $\mathrm{Sim} / \mathrm{Sim} / \mathrm{Sim}$ & $\begin{array}{l}\text { Foi fundado para ser um clube de Cricket mais } \\
\text { democrático, já que os da cidade eram ingleses } \\
\text { exclusivos }\end{array}$ \\
\hline Bahia-BA/Futebol 1931 & Não / Não/ Sim & $\begin{array}{l}\text { A sede social do clube está tão degradada que } \\
\text { não permite mais a prática de esportes, mas } \\
\text { ainda patrocina atletas de outras modalidades }\end{array}$ \\
\hline
\end{tabular}

Os clubes sócio-esportivos são maioria no futebol brasileiro e grande parte das agremiações mais tradicionais possui essa forma de administração, assim como todas que Conexões: revista da Faculdade de Educação Física da UNICAMP, Campinas, v. 11, n. 1, p.188-203, jan../mar. 2013. 194 ISSN: 1983-9030 
participaram do Campeonato Brasileiro da série A no ano de 2011. Alguns dos clubes mais tradicionais, principalmente dos grandes centros urbanos, tiveram início como entidades poliesportivas, como é o caso dos grandes clubes do Rio de Janeiro, que iniciaram suas atividades como clubes de regatas. Essas agremiações possuem até hoje presença marcante em outras modalidades com diversos campeões olímpicos e mundiais. Nesses casos, o futebol teve início como apenas mais uma modalidade e sua administração se desvinculou do resto do clube principalmente por causa da importância que o assumiu atualmente.

Os clubes que adotam esse modelo não possuem um proprietário e sim um presidente escolhido dentre os sócios. Seus membros, em geral, possuem um relacionamento muito antigo com o clube, com início em diversos modos: sendo inseridos pelos pais como sócios; frequentando o clube para praticar alguma modalidade esportiva; com objetivos de convivência social; participando da organização do clube com sua especialidade profissional. Faz-se importante destacar que diversos presidentes atuais são médicos ou advogados que iniciaram sua carreira na administração do clube, na área jurídica ou no departamento médico.

Os clubes sócio-esportivos podem também dedicar-se exclusivamente para o futebol durante toda sua história. Esse modo é comum em agremiações menores e em cidades do interior, mesmo sendo antigas e tradicionais. Sua administração normalmente é idêntica aos clubes tradicionais, com a diferença de que seus membros não se inseriram na entidade como sócios, geralmente sendo pessoas com vínculos mais profundos com a cidade-sede da instituição do que com o clube, freqüentemente empresários ou políticos.

Por sua vez, os clubes-empresa são um fenômeno recente do futebol brasileiro. O primeiro desta categoria foi o União São João, da cidade de Araras/SP em 1994. Mesmo assim eles já possuem uma posição de destaque no futebol, com representantes na série B do Campeonato Brasileiro e em diversas divisões de elite em nível estadual. Sua forma de administração, em modelo de empresa limitada ou sociedade anônima, faz com que possuam as mais diversas finalidades. Pode-se dividi-los em:

Conexões: revista da Faculdade de Educação Física da UNICAMP, Campinas, v. 11, n. 1, p.188-203, jan../mar. 2013.195 ISSN: 1983-9030 
a) clubes tradicionais que adotaram essa forma para aumentar sua eficiência, alguns com sede social transformaram apenas 0 departamento de futebol;

b) equipes com função social, cujo objetivo é formar atletas e dar oportunidade para jovens que não conseguiram firmar posição em grandes clubes e também completar sua educação formal;

c) clubes novos do interior, que buscam ser a equipe representativa da cidade, mas por questões administrativas escolheram começar como empresa; e

d) clubes-empresa que buscam o lucro, formando atletas como produtos para negociação com grandes clubes.

Quadro 2 - Alguns exemplos de clubes-empresa

\begin{tabular}{|c|c|c|}
\hline $\begin{array}{c}\text { Clube / } \\
\text { Campeonato } \\
\text { principal }\end{array}$ & Proprietário & Características \\
\hline $\begin{array}{l}\text { Americana-SP/ } \\
\text { Brasileiro Série B }\end{array}$ & $\begin{array}{l}\text { Sony Alberto } \\
\text { Douer }\end{array}$ & $\begin{array}{l}\text { Fundado pelo empresário em parceria com a } \\
\text { cidade de Guaratinguetá/SP, depois migrou para } \\
\text { Americana/SP }\end{array}$ \\
\hline $\begin{array}{l}\text { Gremio } \\
\text { Barueri- SP/ } \\
\text { Brasileiro Série B }\end{array}$ & $\begin{array}{l}\text { Walter Jorquera } \\
\text { Sanches }\end{array}$ & $\begin{array}{l}\text { O clube teve início como uma ONG na cidade de } \\
\text { Barueri/SP, o clube saiu e voltou para Barueri/SP. }\end{array}$ \\
\hline $\begin{array}{l}\text { Paulista-SP/ Paulista } \\
\text { Série A1 }\end{array}$ & Prefeitura & $\begin{array}{l}\text { Clube tradicional fundado em } 1909 \text {, que optou por } \\
\text { se tornar empresa em } 1995 .\end{array}$ \\
\hline $\begin{array}{l}\text { Ferroviária-SP/ } \\
\text { Paulista Série A-2 }\end{array}$ & $\begin{array}{l}\text { Sociedade } \\
\text { Anônima }\end{array}$ & Clube tradicional. Tornou-se empresa em 2003. \\
\hline $\begin{array}{l}\text { Grêmio Esportivo } \\
\text { Osasco-SP/ Paulista } \\
\text { Série A-3 }\end{array}$ & $\begin{array}{l}\text { Empresários da } \\
\text { cidade }\end{array}$ & $\begin{array}{l}\text { Fundado em } 2007 \text { com o objetivo de ser } \\
\text { representante da cidade. }\end{array}$ \\
\hline $\begin{array}{l}\text { CFZ do Rio-RJ/ } \\
\text { Carioca Série B }\end{array}$ & $\begin{array}{l}\text { Arthur A. } \\
\text { Coimbra - Zico }\end{array}$ & $\begin{array}{l}\text { Fundado para dar oportunidade esportiva a jovens } \\
\text { jogadores, possui filiais em outros estados. }\end{array}$ \\
\hline $\begin{array}{l}\text { Desportivo } \\
\text { Brasil-SP/Paulista } \\
\text { Série B }\end{array}$ & Traffic & $\begin{array}{l}\text { Treina novos jogadores para negociação. Possui } \\
\text { parcerias e investimentos em diversas equipes do } \\
\text { Brasil }\end{array}$ \\
\hline
\end{tabular}

Os clubes-empresa têm em comum o fato de terem um proprietário que pode ser uma pessoa, uma empresa ou um conselho. Em termos práticos isso faz com que o proprietário não precise prestar contas à torcida ou eventuais sócios em relação às suas decisões. Neste caso, a equipe é apenas uma marca, não tendo vínculos com uma cidade ou região, podendo trocar o local de treinamento ou a cidade em que recebe os jogos de acordo com a

Conexões: revista da Faculdade de Educação Física da UNICAMP, Campinas, v. 11, n. 1, p.188-203, jan../mar. 2013. 196 ISSN: 1983-9030 
vontade do mandatário ou por razões financeiras, sem levar em consideração o desejo da torcida. Dois exemplos são os clubes Grêmio Barueri e Guaratinguetá, que criaram um relacionamento forte com a cidade-sede, que lhes emprestou o nome, criando vínculo com a torcida que atuou como consumidora de sua marca e produtos.

Em ambos os casos, a parceria entre empresa e município gerou bons resultados esportivos, tendo o Grêmio Barueri disputado a série A do Campeonato Brasileiro, enquanto que o Guaratinguetá participou da série B. Ambas as relações (equipe/município) acabaram subitamente devido a discordâncias entre as partes. O Grêmio Barueri migrou para a cidade de Presidente Prudente/SP, enquanto o Guaratinguetá firmou nova sede em Americana/SP. Não sem protestos de ambas as torcidas.

Alguns clubes tradicionais, principalmente no interior do estado de São Paulo, optaram por migrar para o modelo de empresa. $\mathrm{O}$ objetivo foi melhorar a administração, otimizar recursos e potencializar o desempenho da equipe. A especificidade desta modalidade é um relacionamento mais próximo com os habitantes da cidade, evitando a mudança para outra localidade. Alguns clubes conseguiram um bom resultado com esta opção, como é o caso do Paulista, da cidade de Jundiaí/SP, agremiação esportiva com mais de 100 anos, que se tornou empresa em 1995, e em 2005 conquistou a Copa do Brasil.

Alguns municípios do interior, principalmente do estado de São Paulo, nutrem o desejo de sediar uma equipe de futebol profissional representando a cidade. Para esses locais, o caminho escolhido tem sido formar um clube-empresa, freqüentemente tendo a prefeitura como proprietária. Esses clubes estão muito presentes na série A2 do Campeonato Paulista e têm conseguido excelentes resultados.

A última categoria apresentada é o de clubes que são constituídos com o objetivo de formar e negociar jogadores, e através desta prática obter lucro. Essas agremiações costumam estar associadas a empresas que já atuam no ramo do futebol. Um exemplo é o Desportivo Brasil, cuja proprietária é a empresa Traffic, que possui direitos econômicos de diversos jogadores. O clube possui um centro de treinamento de excelência na cidade de Porto Feliz/SP.

Conexões: revista da Faculdade de Educação Física da UNICAMP, Campinas, v. 11, n. 1, p.188-203, jan../mar. 2013.197 ISSN: 1983-9030 


\section{Perfil dos presidentes de clubes de futebol masculino profissional no Brasil}

Analisando a trajetória dos presidentes dos principais clubes do Brasil (participantes do Campeonato Brasileiro séries A e B, e Campeonato Paulista, séries A1 e A2) percebe-se que o quadro é complexo, as suas características variam de acordo com a equipe e a minoria se dedica à política profissional.

O grupo é muito diversificado, mas é possível reunir algumas características em comum. Talvez a de maior destaque seja a fidelidade. Em todos os clubes analisados os presidentes atuaram unicamente na sua agremiação, não havendo nenhum caso de troca.

Outra característica marcante é que esse sub-campo social é dominado majoritariamente por empresários. Eles são 12 nos 20 clubes da Série A do Campeonato Brasileiro, com mesmo número na Série B, 7 presidentes nos 20 clubes da série A1 do Campeonato Paulista e 8 sujeitos na série A2 do mesmo estado.

Os casos de corrupção e de crimes são uma exceção. Apesar da divulgação por parte da mídia, o que transmite a impressão de freqüência, são raros os presidentes no cargo que enfrentam processos ou são exonerados. O mais comum, quando ocorre, é a descoberta de alguma discrepância quando são analisadas as contas da gestão anterior, e mesmo nesse caso a situação normalmente é duvidosa, pois os processos podem estar mais ligados a disputas entre grupos políticos internos do que crimes propriamente ditos.

A série A do Campeonato Brasileiro é composta, majoritariamente, pelos clubes tradicionais, ou seja, os clubes mais antigos e com história de títulos tanto em nível nacional, quanto regional. A liderança política nestes clubes é caracterizada, principalmente, por uma longa história de participação, que pode variar de algumas décadas até relacionamentos que começam com os pais ou avós.

Alguns presidentes começaram seu envolvimento com o clube pela via esportiva, como é o caso de Patrícia Amorim, presidente do Flamengo, que competia em natação pelo clube, ou de Peter Siemsen, que competia em tênis e iatismo no Fluminense. Casos de ex-jogadores 
de futebol profissionais que galgaram a ascensão dentro da hierarquia do clube são raros. Um exemplo é Roberto Dinamite, ex-jogador, ídolo e atual presidente do Vasco da Gama.

O cargo de presidente e as atividades políticas nos clubes sócio-esportivos raramente são remunerados. Assim, todos os membros possuem uma atividade profissional externa à instituição. A mais comum é a empresarial, geralmente atuando no grupo social ou político fundado por ele próprio ou por sua família. Outros são profissionais liberais, como médicos, dentistas ou advogados. A carreira política é rara, sendo que apenas 6 dos 20 presidentes da divisão de elite têm ou tiveram alguma atuação política externa à entidade.

A série $\mathrm{B}$ do Campeonato Brasileiro guarda características mistas entre a série A e as competições regionais. Ela possui clubes de expressão de centros importantes, como Salvador ou Recife, que mesmo não estando no primeiro escalão jogam as séries principais com frequência e têm características semelhantes às dos clubes mais tradicionais. Como também se pode encontrar na Série B do campeonato nacional equipes com características mais próximas de clubes regionais, como é o caso do Bragantino, da cidade de Bragança Paulista/SP.

Os clubes que atuam em nível regional, representados nesta pesquisa pelos participantes das séries A1 e A2 do Campeonato Paulista, possuem particularidades próprias. Apesar de manterem as características dos dirigentes de outras equipes (empresários ou profissionais liberais), a sua lealdade muda. Nos clubes regionais o relacionamento é mais forte com a cidade do que com o clube propriamente dito, o que em termos práticos não altera muito a situação, pois frequentemente aquele é o único time profissional da região. Isso é demonstrado de várias formas. Geralmente os empresários estão ligados à história e organização da cidade.

Outro caminho que entrelaça a cidade com os dirigentes é a política, diversos clubes do interior recebem ajuda da prefeitura e os administradores que conseguem capitanear a liberação destes recursos acabam se envolvendo com a entidade também.

Conexões: revista da Faculdade de Educação Física da UNICAMP, Campinas, v. 11, n. 1, p.188-203, jan../mar. 2013. 199 ISSN: 1983-9030 
As características descritas no parágrafo anterior só estão divididas de forma tão delimitada em casos raros. O mais comum é que todas elas estejam misturadas, pois as cidades menores costumam ter uma vida econômica, política e social menos complexas do que os grandes centros. Isso faz com que frequentemente presidentes de clubes sejam ligados a políticos, que são próximos da empresa mais próspera da cidade, com laços de amizade ou familiares.

Do mesmo modo que se pode apontar, conforme sugere Bourdieu, ${ }^{4}$ que o esporte moderno teve sua origem em práticas de diferenciação social elitistas, percebe-se que os critérios para o alcance do posto de presidente de clubes de futebol profissional mantêm tal característica. Independente da categoria de clube (sócio-esportivo ou empresa), o capital simbólico deste sub-campo apresenta-se com base na legitimidade que o sujeito agrega em relação à cultura própria da instituição. Ou seja, percebe-se que nas entidades de cunho sócio-esportivo, o habitus da classe dominante remete ao vínculo familiar, político e emocional com a agremiação. A história de envolvimento do agente social com o clube faz-se um critério importante e considerado, principalmente em grandes centros, talvez devido à presença de um número maior de clubes profissionais na cidade.

De forma próxima, pode-se citar o habitus diferenciado dos presidentes de clubes sócioesportivos de cidades menores, nas quais o envolvimento com a entidade não parece ser um capital simbólico tão decisivo e valorizado quanto a ligação e popularidade do sujeito com o município e o grupo social próprio.

Em clubes-empresa percebe-se um habitus diferenciado, ligado ou à cidade-sede do mesmo ou à capacidade gestora e profissional do sujeito. Percebe-se grande influência do capital social adquirido na entidade para a ascensão em clubes sócio-esportivos, e de capital cultural e econômico em clubes-empresa.

Independente da categoria de clube, o capital esportivo do agente é pouco valorizado para a chegada ao posto de presidente. Os feitos como atleta, em geral, não garantem privilégios sociais nem legitimidade institucional que direcionem o sujeito a ascensão política dentro 
da entidade. Raros são os casos em que o atual presidente de clube foi um atleta de destaque dentro da instituição.

Outro fator generalizante entre os presidentes de clubes de futebol profissional analisados é que eles fortalecem a perspectiva distintiva, elitista e segregadora que Bourdieu ${ }^{5}$ denuncia como critério de distribuição de capital nos campos sociais. $\mathrm{O}$ autor francês descreve que tais regras de acesso ao capital simbólico nos campos respeitam as vontades e habitus da classe dominante no mesmo. O que indica uma luta entre o novo, que busca se introduzir e tenta forçar o direito de entrada no espaço social - que consiste no reconhecimento do valor e no conhecimento dos princípios de funcionamento do jogo, ou seja, sobre a história das disputas, que se encontram presentes nas relações - e o dominante, que tenta defender o monopólio e excluir a concorrência. ${ }^{6}$

Desse modo, nota-se que em muitos clubes existe uma transição de poder quase que hereditária entre agentes ou grupos sociais com habitus semelhantes, o que dificulta a entrada de novos agentes externos a tais classes.

Bourdieu $^{6}$ aponta que uma característica importante dos campos, e consequentemente dos sub-campos, é que eles se compõem de modo relativamente autônomo em relação ao espaço social macro (a sociedade como um todo). Além disso, cita que alguns tipos de capitais sejam mais valorizados em determinados ambientes do que em outros, e que não existe uma transferência direta entre a posição social de um sujeito de um campo para outro, podendo o mesmo agente fazer parte de uma elite em um espaço social e de um grupo segregado em outro. Embora isso seja observável e comprovável, percebe-se que os presidentes de clubes de futebol profissional analisados possuem também posição de destaque em outros campos da sociedade, principalmente na economia, política e profissional. Isso acaba sendo fortalecido pela perspectiva amadora elitista ainda presente nos clubes sócio-esportivos, e a necessidade de lucros no clube-empresa.

Pode-se apontar, então, que o sub-campo do futebol profissional, mais especificamente o espaço de atuação dos presidentes de clubes, tem suas regras e características próprias de distribuição de capital e de atuação social. Por exemplo, questões como nepotismo e 
perpetuação familiar de poder são mais aceitas do que na política fora deste espectro. Nos clubes sócio-esportivos nota-se que questões emocionais e vínculos afetivos mostram-se critérios importantes para a ascensão social, o que não se observa em outros campos da sociedade. No caso dos clubes-empresa, nota-se uma ligação maior com a capacidade profissional do sujeito, aproximando ainda mais os critérios deste sub-campo ao espectro social maior.

Porém, o espaço de atuação dos presidentes de clubes profissionais de futebol respeita em muito alguns capitais simbólicos valorizados em outros campos sociais, o que indica que este ambiente tenha suas particularidades, mas ainda assim utiliza-se de critérios diversificados para a delegação de legitimidade social a seus agentes.

\section{OBSERVAÇÕES FINAIS}

A pesquisa sistemática sobre os presidentes dos principais clubes de futebol do Brasil, destacando dimensões pessoais, profissionais e políticas de cada um deles, características materiais e simbólicas do contexto organizacional em que atuam e o campo do esporte, permite uma compreensão profunda das relações presentes, assim como das componentes fundamentais destes agentes enquanto elemento auxiliar para a reflexão e a pesquisa sobre futebol.

O presidente do clube de futebol profissional age no interior de uma organização de natureza formal e burocrática, inserida no espaço maior da sociedade, onde se destacam as dimensões sociais, políticas e econômicas. Esta organização formal, o clube, compartilha uma herança histórica comum ao participar da esfera esportiva, mais especificamente futebolística. A compreensão que o agente social tem do ambiente, neste caso o presidente de um clube de futebol, delimita-se a partir de sua história, cultura organizacional e percepção coletiva da dimensão simbólica das relações individuais e institucionais.

A pessoa do presidente do clube de futebol ilustra a interface entre as diferentes dimensões que caracterizam o campo esportivo, a evolução de uma modalidade esportiva em particular e a cultura de uma organização específica. A inserção no contexto social mais Conexões: revista da Faculdade de Educação Física da UNICAMP, Campinas, v. 11, n. 1, p.188-203, jan../mar. 2013. 202 ISSN: 1983-9030 
amplo traz consigo a presença de uma contemporaneidade marcada pelas contradições e conflitos que a caracterizam.

\section{REFERÊNCIAS}

${ }^{1}$ GALATTI, L. R. Esporte e clube sócio-esportivo: percurso, contextos e perspectivas a partir de estudo de caso em clube esportivo espanhol. 2010. Tese (Doutorado em Educação Física) - Faculdade de Educação Física, Universidade Estadual de Campinas, Campinas, 2010.

${ }^{2}$ PUIG, N. et al. Propuesta de marco teórico interpretativo sobre el asociacionismo deportivo en España. Motricidad, v. 2, p. 75-92,1996.

${ }^{3}$ HEINEMANN, K. Sociología de las organizaciones voluntarias: el ejemplo del club deportivo. Valencia: Tirant to Blanch, 1999.

${ }^{4}$ BOURDIEU, P. Coisas ditas. São Paulo: Brasiliense, 1990.

${ }^{5}$ BOURDIEU, P. Razões práticas: sobre a teoria da ação. Campinas: Papirus, 1996.

${ }^{6}$ BOURDIEU, P. Questões de sociologia. Rio de Janeiro: Marco Zero, 1983.

Apoio financeiro do LUDENS/USP - Núcleo Interdisciplinar de Pesquisas sobre Futebol e Modalidade Lúdicas.

Recebido em: 12 jul. 2012

Aceito em: 12 fev. 2013

Contato: Renato Francisco Rodrigues Marques renato.marques@yahoo.com.br

Conexões: revista da Faculdade de Educação Física da UNICAMP, Campinas, v. 11, n. 1, p.188-203, jan../mar. 2013. 203 ISSN: 1983-9030 